\title{
OS MOVIMENTOS SOCIAIS CONTEMPORÂNEOS E AS ESCALAS DE AÇÃO: DA GEOPOLÍTICA AO MUNDO VIVIDO
}

\author{
Ana Carolina de Oliveira Marques ${ }^{1}$ \\ Eguimar Felício Chaveiro \\ Rusvênia Luiza Batista Rodrigues da Silva ${ }^{3}$
}

\begin{abstract}
Resumo: Desde a dimensão miúda e rente das práticas do sujeito até às dimensões geopolíticas, incluindo o entrecruzamento das escalas, os Movimentos sociais agem no espaço, são condicionados por ele, desenvolvem práticas espaciais, dão o sentido de suas lutas, lutam por espaços. Propõe-se, a partir deste artigo, contribuir à reflexão dos movimentos sociais como atores territoriais, cuja intervenção não se encerra no campo macropolítico. Este texto corresponde a um fragmento da tese de doutorado intitulada "Cartografia das Moradias em Canudos: a dimensão política do morar", logo deriva de uma pesquisa qualitativa realizada junto a assentados de reforma agrária. Na tese, também os acampamentos compuseram o objeto de estudo, daí a experiência da ocupação de um latifúndio no interior de Goiás (município de Corumbá) como ponto de partida das reflexões suscitadas ao longo deste texto.
\end{abstract}

Palavras-chave: movimentos sociais; geopolítica; prática espacial.

\section{THE CONTEMPORARY SOCIAL MOVEMENTS AND THE SCALES OF ACTION: FROM GEOPOLITICS TO THE LIVED WORLD}

Abstract: From the small and close dimension of the subject's practices to geopolitical dimensions, including the intersection of scales, social movements act in space, are conditioned by it, develop spatial practices, give meaning to their struggles, fight for spaces. It's proposed, through this article, to contribute to the reflection of the contemporary social movements as territorial actors, whose intervention does not end in the macro political field. This paper is part of the doctoral thesis titled "Cartography of the Houses in Canudos: the political dimension of housing", and derives from a qualitative research carried out with settlers of agrarian reform. In the thesis, the camps also composed the object of study, hence the experience of the occupation of a latifundium in the interior of Goiás (municipality of Corumbá) as a starting point for the reflections raised throughout this text.

Keywords: social movements; geopolitics; spatial practice.

\footnotetext{
${ }^{1}$ Docente da Universidade Estadual de Goiás. carol.geografia@ @otmail.com

${ }^{2}$ Docente da Universidade Estadual de Goiás. eguimar@ hotmail.com

${ }^{3}$ Docente no Centro de Pesquisa Aplicado à Educação (CEPAE-UFG). rusvenia@gmail.com

Estudos Geográficos, Rio Claro, 16(2): 126-122, jul./dez. $2018 \quad$ (ISSN 1678 -698X) http://www.periodicos.rc.biblioteca.unesp.br/index.php/estgeo
} 


\section{INTRODUÇÃO}

Líderes do MST de Goiás na secretaria do Movimento, em Goiânia, promovem uma reunião. Na pauta um item de operação tática: ver que a conjuntura social e econômica do país é factível às ocupações. Para isso, deve-se ajuntar os membros que sairão à periferia da cidade, sob organização prévia, e colocarão em prática oficinas de contatos com trabalhadores. Essas oficinas, comandadas pela frente de massa, além de falarem da conjuntura, lerem a estrutura do modo de produção capitalista, ouvirem o sentimento do trabalhador, deverão criar meios para que os trabalhadores informais, desempregados, precarizados constituam frentes de ocupações. As oficinas são o chamamento à luta, o despertar da consciência do trabalhador sofrido à sua condição e situação de classe. Para isso têm uma direção: sensibilizar o trabalhador em direção à esperança concreta, histórica, não metafísica.

Para isso, outro grupo de lideranças, em fiel contato com este, num trabalho de sondagem, pesquisa e comunicação, e também de interpretação cartográfica, já escalou alguns latifúndios passíveis de serem ocupados. Especialmente, o trabalho do grupo de sondagem é estratégico, perigoso. Todos os cuidados deverão ser tomados. Qualquer vazamento de informação, o que já ocorreu, pode levar os latifundiários a buscarem o setor da política hegemônica, da polícia e dos centros produtores de ideologias, como TVs, Jornais, Igrejas e brecarem a ocupação, inclusive com ameaças de morte ou mesmo com assassinatos e perseguições de lideranças.

O trabalho cartográfico de observação do latifúndio a ser ocupado não basta. Convém também observar "os pontos fortes da propriedade" e os "pontos fracos". O tamanho, a oferta de águas, a qualidade do solo, a rede viária, a situação da produção, a aptidão agronômica - e outros quesitos - deverão ser observados. Diz um líder: "a ocupação não é coisa de criança, não, precisa valer a pena, há risco de morte, há vidas correndo risco...".

Antes da ocupação, a partir da leitura da propriedade, inclusive de sua história, de quem é o proprietário, seus vínculos políticos, sua força de articulação, as frentes do MST estabelecem um arco de poder para formar o acampamento. Este significa um avanço da frente de massa no sentido de dar um passo no processo organizativo cujo destino é a ocupação e depois a distribuição da terra.

A partir da ocupação de terras, vivenciada pelos autores deste artigo, que deu origem ao Acampamento "Dom Tomás Balduíno", no município de Corumbá (Goiás), algumas reflexões foram suscitadas acerca da relação entre a Geografia e os Movimentos Sociais, ou a dimensão espacial dos Movimentos Sociais, já elaborada por intelectuais porém deficiente de um consenso.

Revisão de teses, registro fotográfico, relatos de lideranças populares foram compilados neste texto no intuito de atender a dois objetivos: primeiro, apresentar um texto de fácil leitura que sirva de apoio à estudantes de Geografia na compreensão dos movimentos sociais enquanto atores territoriais; segundo, contribuir para uma leitura geográfica dos movimentos sociais para além da dimensão macropolítica, desvendando as práticas espaciais como campos fundamentais na construção de sentidos e da desejada revolução molecular.

Estudos Geográficos, Rio Claro, 16(2): 101-140, jul./dez. $2018 \quad$ (ISSN 1678-698X) http://www.periodicos.rc.biblioteca.unesp.br/index.php/estgeo 


\section{OS MOVIMENTOS SOCIAIS E A GEOGRAFIA}

Relatou-se, no início do texto, o conjunto de ações que definem o Movimento Social. Maria da Glória Gohn (2008, p. 14), afirma que:

Um movimento social é sempre expressão de uma ação coletiva e decorre de uma luta sociopolítica, econômica ou cultural. E tem os seguintes elementos: demandas que configuram sua identidade, adversários e aliados, bases, lideranças e assessorias - que se organizam em articuladores e articulações e formam redes de mobilizações, práticas comunicativas diversas que vão da oralidade aos modernos recursos tecnológicos, projetos ou visões de mundo que dão suporte a suas demandas, e culturas próprias nas formas como sustentam e encaminham suas reivindicações.

Assim, na elaboração do acampamento, novamente é necessário ler o território, ver onde as barracas deverão ser montadas. Quesitos de primeira ordem como água, possibilidade de instalação de barracas, capacidade de comunicação com as cidades e condições de provimento de alimentos se juntam aos estratégicos: condições de avançar e de evacuar, possibilidades de organizar oficinas de formação, montagem de grupos de trabalho e de comissões que, num raio democrático, inserem todos numa tática de solidariedade e de aproximação. Assim surgem as comissões estratégicas, de segurança, de negociação, de formação, de higiene, de animação, de alimentação, de saúde.

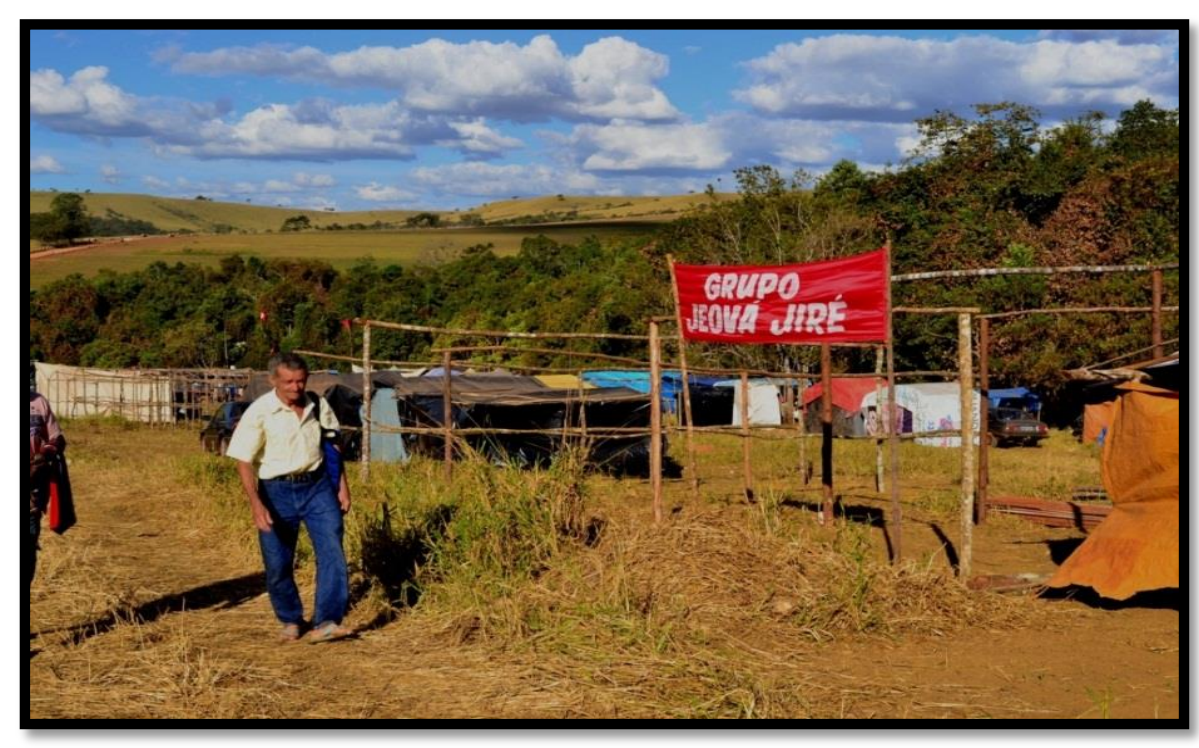

Estudos Geográficos, Rio Claro, 16(2): 101-140, jul./dez. $2018 \quad$ (ISSN 1678-698X) http://www.periodicos.rc.biblioteca.unesp.br/index.php/estgeo 


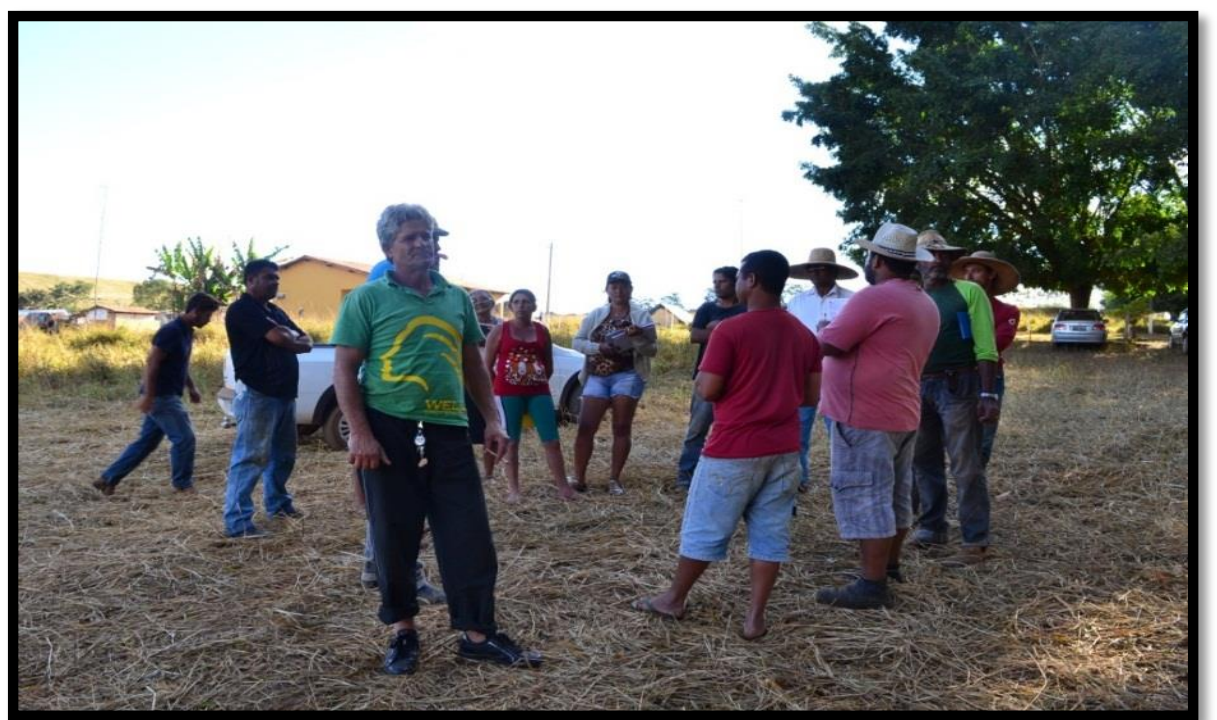

Imagem 1 e 2 - Acampamento "Dom Tomás Balduíno" - Corumbá de Goiás, $2015^{4}$.

Fonte: AUTOR, 2015.

Pode também, no meio de lonas, estacas, baldes, botijões de gás, pequenas trempes, serem formados grupo de mulheres, de crianças. O local do acampamento, como prenúncio de uma ocupação, deverá ser inteligente, estratégico. O acampamento surge como um território de preparação, ou de luta, e também de vida. Por isso, o espírito de solidariedade, a consistência dos princípios do Movimento, a leitura crítica da conjuntura, as festas, a reunião com os "amigos do Movimento", a celebração religiosa, a visita de deputados e autoridades que são favoráveis à causa, de estudantes, professores universitários e de outros segmentos vão agindo na consciência, e "ganhando terreno" para, num momento acordado, o latifúndio ser ocupado.

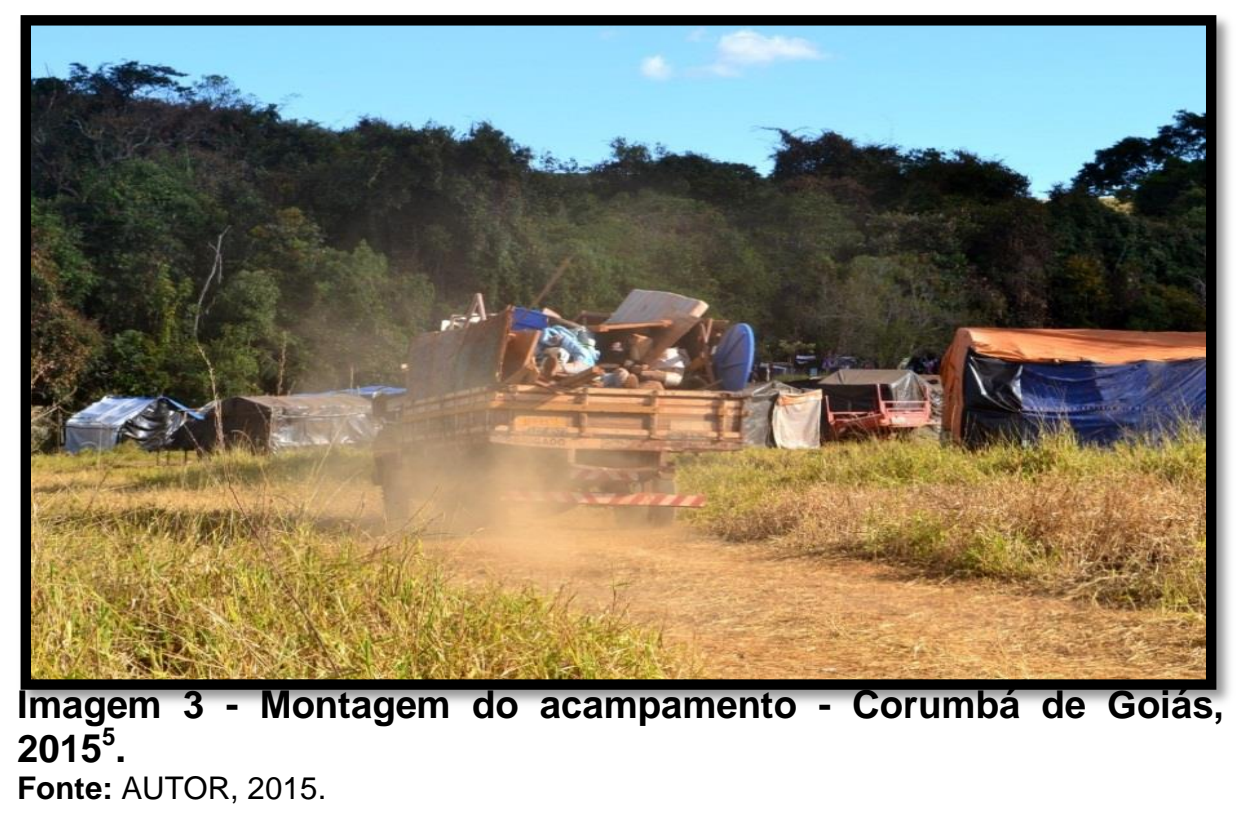

\footnotetext{
${ }^{4}$ Armação das barracas e reuniões dos representantes de grupos no primeiro dia no acampamento Dom Tomás Balduíno, Fazenda Santa Mônica, 2015.

${ }^{5}$ Transporte dos materiais utilizados na construção das barracas.

$\begin{array}{llllllll}\text { Estudos Geográficos, } & \text { Rio } \quad \text { Claro, } & \text { 16(2): } & 101-140, & \text { jul./dez. } & 2018 & \text { (ISSN } & 1678-698 X)\end{array}$ http://www.periodicos.rc.biblioteca.unesp.br/index.php/estgeo
} 
O cordão de pessoas, sob orientação, segue com definições dos papéis a serem desempenhados. O momento de sair do lugar de organização à ocupação, o trajeto, os veículos que conduzirão os ocupantes, as frentes de segurança, os cuidados da caminhada, as místicas de reforços subjetivos, o tipo de armamento que dará suporte aos ocupantes, até o chute simbólico na cerca do latifúndio ocupado transforma a tensão e os perigos numa valência territorial: o pulo do acampamento ao assentamento.

Todavia, para sedimentar o assentamento outros tantos passos, lutas, articulações, conflitos jurídicos e políticos são delineados dia a dia. O fato é que a luta do MST, suas táticas, conquistas de horizontes curtos, a terra; e seus fins de horizonte largos, a reforma agrária e a construção do socialismo, incluindo as hesitações, o debate público, as contradições internas e externas, possui uma ligação direta com a lógica, a organização e a estruturação territorial.

Este fato e essa leitura, feita há mais de 30 anos, cria duas situações: a aproximação de setores, líderes, membros do $\mathrm{MST}^{6}$ aos geógrafos e curso de geografia; e a aproximação, pesquisas, estágios de vivências, atividades de extensão, trabalhos de campo de geógrafos nos acampamentos e assentamentos do MST. Isso mobilizou uma gama de geógrafos a estabelecerem teorizações geográficas sobre, não apenas o MST, mas sobre a dimensão espacial ou territorial dos Movimentos Sociais.

\section{A DIMENSÃO INSTITUCIONAL}

Geógrafos de diferentes segmentos teóricos e políticos, além de disciplinas, grupos de pesquisas, áreas de concentração de pós-graduação geraram uma compreensão: os Movimentos Sociais são agentes, atores ou sujeitos territoriais. Por isso, o que está posto não são apenas estratégias territoriais dos Movimentos em suas lutas, mas a sua ação na construção, na mudança e na formação de conteúdos territoriais dos lugares, municípios, regiões.

De acordo com Porto-Gonçalves e Seoane (2003), as táticas empreendidas por movimentos sociais intentam modificar a configuração espacial dada, uma vez que toda demanda social é uma demanda por espaço. A essa correlação, o autor denomina "geograficidade do social".

Emerson Santos (2006), em sua tese de doutorado dedicada ao estudo dos programas de Pré-vestibular para negros e carentes, dedicando um capítulo à relação movimento social e geografia. Propôs uma taxonomia na qual três tendências foram manifestas: 1. A Geografia da organização dos movimentos sociais; 2. A Geografia das lutas sociais; 3. A Geo-grafia dos movimentos sociais.

A primeira compreende o movimento social como objeto de estudo. A escala de análise predominante está circunscrita aos limites político-administrativos: bairros, cidades, assentamentos, municípios, estados, países, lotes, regiões de planejamento.

A segunda tendência tem no movimento social o motivador dos estudos, não compondo necessariamente o objeto de pesquisa. A leitura classista predomina em tal tendência, sendo a principal crítica tecida por E. Santos (2006) à "Geografia das lutas sociais", a tendente ocultação das formas de luta e ativismo não baseados na conflitividade.

\footnotetext{
${ }^{6}$ Ressaltamos que o enfoque dado ao Movimento dos Trabalhadores Rurais Sem-Terra, a título de exemplificação, não destitui a importância dos demais movimentos sociais.

Estudos Geográficos, Rio Claro, 16(2): 101-140, jul./dez. $2018 \quad$ (ISSN 1678-698X) http://www.periodicos.rc.biblioteca.unesp.br/index.php/estgeo
} 
Por fim, a terceira tendência: a Geo-grafia dos movimentos sociais. Nesta, busca-se construir um cabedal conceitual a partir do "revisionismo das velhas utopias", compondo referenciais teóricos provenientes de experiências sociais concretas. Desse investimento, resultam proposições analíticas como a elaborada por Pedon (2013): movimentos socioterritoriais.

Pode-se, a partir do diretório de grupos de pesquisa do Conselho Nacional de Desenvolvimento Científico e Tecnológico (CNPq, 2016), construir um mapa (vide mapa 1) dos estudos de movimentos sociais no âmbito da Geografia, no ano de 2016. O critério fora a ocorrência da palavra "movimento social" nos títulos, linhas de pesquisa e palavras-chave presentes na ficha cadastral dos grupos.

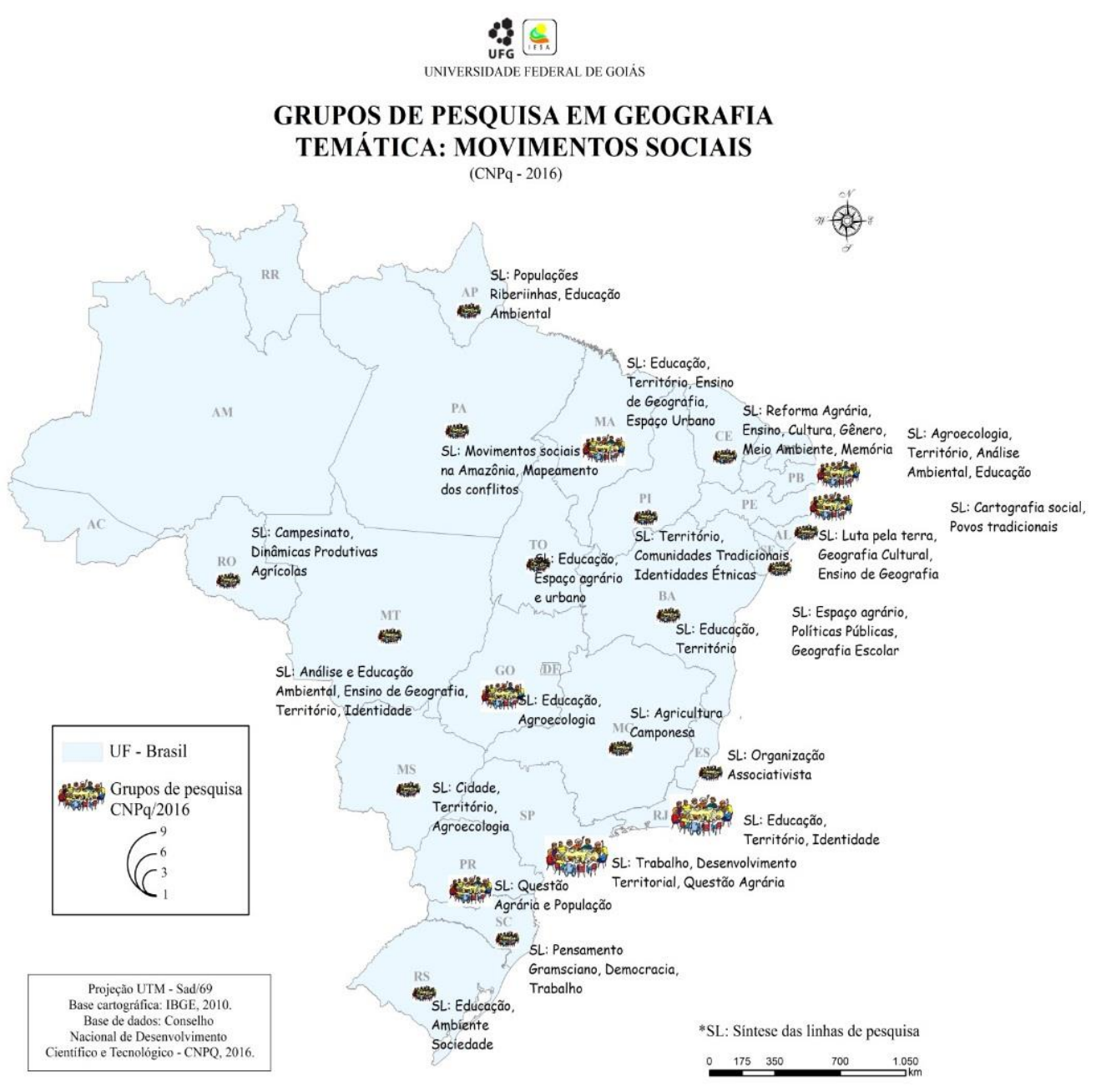

\footnotetext{
Mapa 1 - Grupos de Pesquisa em geografia com a temática "Movimentos Sociais" - 2016

Cartografia digital: Ana Carolina de O. Marques, 2016.
}

Estudos Geográficos, Rio Claro, 16(2): 101-140, jul./dez. $2018 \quad$ (ISSN 1678-698X) http://www.periodicos.rc.biblioteca.unesp.br/index.php/estgeo 
Sob o risco das generalizações, identificam-se três tendências da aproximação entre Geografia e Movimentos Sociais.

A primeira e menos expressiva em quantidade de grupos, tem como base territorial os estados do Pará e Amapá. A unidade dos grupos se encontra na ênfase à interação entre as populações e a biodiversidade local. Os movimentos sociais, nesse sentido, são mecanismos de representação e proteção socioambiental acionados por povos ribeirinhos, indígenas etc; cujo bem-estar social demanda 0 reconhecimento das economias - materiais e simbólicas - ancoradas aos territórios historicamente habitados. Na taxonomia de E. Santos (2006), estes grupos se enquadrariam na "Geografia das lutas sociais".

A segunda tendência consolida-se nas instituições no Nordeste brasileiro. Tem o espaço agrário como unidade de análise predominante, porém sua marca é a diversidade. Educação no campo, políticas públicas, luta pela terra, ensino de geografia, comunidades tradicionais, identidades étnicas entre outros temas são atrelados aos movimentos sociais.

A terceira tendência apresenta-se em formato de rede, materializada em estados expoentes do agronegócio brasileiro: Goiás, Mato Grosso do Sul, Minas Gerais, São Paulo, Paraná, Santa Catarina e Espírito Santo. Predomina uma perspectiva de denúncia da precarização do trabalho e dos danos ambientais causados pela absorvente territorialização do capital.

Dentre as proposições dos geógrafos desta última tendência, tem-se o movimento social enquanto categoria geográfica, defendida por Bernardo Mançano Fernandes:

\begin{abstract}
Estudar um movimento social como categoria geográfica é condição essencial para a elaboração da teoria. Categorias são conceitoschave de uma ciência.... São conceitos fundamentais construídos desde a análise das experiências desenvolvidas na realidade até aos esforços lógicos para a elaboração de leituras e construção de ensaios teóricos.... Movimentos sociais podem ser categorias de diferentes áreas do conhecimento, desde que os cientistas construam os respectivos referenciais teóricos. Esse é o nosso desafio na Geografia. Os movimentos sociais constroem estruturas, desenvolvem processos, organizam e dominam territórios das mais diversas formas $(2000$, p. 60$)$.
\end{abstract}

A defesa de que "um movimento social" é uma categoria geográfica sofre rebatimento crítico. Pode-se, por exemplo, compreender que tal posição induz a uma confusão entre o mundo e a ideia de mundo. Num horizonte abrangente todos os temas seriam categorias geográficas. Mesmo que pese a ideia do autor seja alvo de uma reflexão, como qualquer ideia e qualquer representação, o que vale é a afirmação final: "Esse é o nosso desafio na Geografia. Os movimentos sociais constroem estruturas, desenvolvem processos, organizam e dominam territórios das mais diversas formas".

A interferência concreta dos Movimentos Sociais na transformação do território, de fato, é um dado, assim como a sua organização feita por escalas internacionais, contudo há outras dimensões, como o projeto de país e o projeto de sociedade. A vertente ideológica, em se tratando da ação e da elaboração dos Movimentos Sociais, todavia, só tem sentido a partir das práticas espaciais.

Estudos Geográficos, Rio Claro, 16(2): 101-140, jul./dez. $2018 \quad$ (ISSN 1678-698X) http://www.periodicos.rc.biblioteca.unesp.br/index.php/estgeo 


\section{A DIMENSÃO DAS PRÁTICAS ESPACIAIS}

O geógrafo Marcelo Lopes de Souza observa a dimensão espacial das lutas e as práticas espaciais primeiramente a partir de uma escala global: os Movimentos Sociais agem naquilo que é o produto nefasto da divisão internacional do trabalho. Por conseguinte, a dimensão espacial refere-se ao modo como, em termos de estrutura, está estabelecido o sentido geopolítico entre o mundo capitalista rico e pobre. Diz o autor

As especificidades sociais do Primeiro e do Terceiro Mundo materializam-se no espaço, com vínculo forte com o tipo e a dinâmica dos ativismos. Além de circunscrita em termos de grupo social, a pobreza tende a ser, no Primeiro Mundo, limitada em termos espaciais. Já no Terceiro Mundo, com a pobreza sendo generalizada temos também a sua difusão pelo espaço urbano, através de situações as mais diferentes: periferias, favelas centralmente localizadas, áreas de obsolescência. Assim, no Terceiro Mundo, sem que se desconheça uma problemática e um tipo de ativismos mais próximos dos primeiromundistas, o que ocorre é que a sua importância é em grande parte eclipsada pela gravidade e pela importância quantitativa dos problemas fundamentais que vitimam os trabalhadores pobres (SOUZA, 1988 p. 152-153).

Se a pobreza, a desigualdade social, a concentração de renda, a formação e a manutenção do latifúndio, a segregação espacial são produtos da divisão internacional do trabalho, a leitura e o enfrentamento desses problemas passam pela leitura espacial. A geógrafa Tatiana Tramontani Ramos (2013), referindo-se ao Movimento Sem-Teto, disserta sobre "a dimensão espacial das lutas sociais".

Ao reportar aos geógrafos que, num viés crítico, têm investigado o assunto, a autora expõe alguns pontos que marcam a relação entre Movimentos Sociais e espaço. Dentre os pontos, a autora menciona: a noção de espaço vivido mediante a qual dimensões de identidade de classe, racial, de gênero e também campos da subjetividade e da intersubjetividade compreendem o mundo concreto das relações entre os sujeitos; a organização hegemônica do espaço, com ações do planejamento feito pelo Estado, empresas, corporações; os aspectos concretos do espaço, tais como vias, equipamentos, infraestrutura, problemas ambientais, equipamentos de consumo, especulação imobiliária; localização e possibilidades de comunicação.

Enfim, desde a dimensão miúda e rente das práticas do sujeito até às dimensões geopolíticas, incluindo o entrecruzamento das escalas, os Movimentos sociais agem no espaço, são condicionados por Ele, desenvolvem práticas espaciais, dão o sentido de suas lutas, lutam por espaços.

A partir das diferentes práticas espaciais os Movimentos Sociais, em geral, e - Movimento dos Trabalhadores Rurais Sem Terra, mostram-se vivos e dizem, na práxis, o que são. Desenvolvendo as suas práticas espaciais é que o horizonte de sua utopia se consagra como mundo vivido. É também nas práticas espaciais que expõem os seus conflitos internos e expressam o repertório de suas conquistas frente aos conflitos sociais externos. Ou seja: os conflitos externos, por exemplo, as lutas de classe, o processo de alienação, as estratégias de captura ideológica, os

Estudos Geográficos, Rio Claro, 16(2): 101-140, jul./dez. $2018 \quad$ (ISSN 1678-698X) http://www.periodicos.rc.biblioteca.unesp.br/index.php/estgeo 
hábitos e as representações culturais e simbólicas são vividos no trabalho, nas relações afetivas, na organização política e na significação do morar.

\section{MOVIMENTOS SOCIAIS CONTEMPORÂNEOS: O CÍRCULO DO CONFLITO E DA DIVERSIDADE}

Conforme analisa Chesnais (1999), no pós-guerra, o capitalismo, por meio de empresas dos EUA e da Europa ocidental, ao acumular uma monta enorme de capitais, desenvolveu estratégias de investir os excedentes de duas maneiras: uma expansão fora do país de origem e o investimento no setor produtivo. Essas duas estratégias davam curso ao processo de mundialização do capital garantido a continuidade do modelo de acumulação.

Era necessário, com base nessas estratégias, sofisticar o processo de acumulação aglutinando o setor produtivo ao financeiro. Foram com essas estratégias que constituíram a mundialização do capital. O que trouxe sérias implicações à questão da moradia, entre elas, a financeirização da moradia (ROLNIK, 2015).

A mundialização, aos poucos, contudo com gana, guerra, bloqueios, aliciamentos, ocupou-se em desenvolver transações financeiras, monopólios de empresas, deslocamento de empresas, pressão sobre Estados, assassinatos de líderes opostos. Intenta-se o desmonte das organizações sociais historicamente atuantes por diferentes vias: cooptação, prisão etc.

Em função disso casou-se a estratégia de acumulação que rogava pela livre circulação do capital financeiro à mudança do Estado, dando-Ihe uma feição neoliberal. O chamado enxugamento da máquina estatal, o financiamento das megaempresas especialmente na construção e reparos de obras de infraestruturas os megaprojetos -, o processo de privatização, o controle da contabilidade financeira do Estado, o processo de terceirização dos vínculos do trabalho, exigiam a desregulamentação dos mercados e a liberalização da economia.

Era evidente que para o capital se mundializar os aportes da ciência e da tecnologia seriam necessários. Com esses aportes seria possível, num só golpe, estabelecer barreiras para o trabalho e derrubar os muros para a ação do capital. Ainda que o processo de desterritorialização global do trabalho soasse como produto indigesto dessa armação, e surgissem movimentos de trabalhadores de diferentes lugares e para diferentes sentidos deslocando-se em busca de emprego e de sobrevivência, o que mundializava, de fato, era o capital e não os trabalhadores. Poder-se-ia mencionar que estava estabelecido um novo desenho da luta de classes.

Todas as iniciativas, entre as quais, a ordem da estabilização monetária; a subordinação das moedas locais ao dólar; o incremento do sistema viário; a abertura de fronteiras para o cultivo de produtos de exportação; a modernização do parque técnico-científico; a organização de zonas seletivas competitivas; a abertura dos mercados para a ação direta do comércio internacional; a construção de plataformas tecnológicas para atrair capitais estrangeiros; a subvenção fiscal às empresas e aos conglomerados estrangeiros - e outras iniciativas - confirmavam, o que Santos (2003) sintetizava: o Estado agia para transformar o território nacional numa economia do capital internacional.

Além do novo desenho da luta de classes e da alteração vertiginosa da morfologia do trabalho com o incremento da agricultura de precisão; da inseminação

Estudos Geográficos, Rio Claro, 16(2): 101-140, jul./dez. $2018 \quad$ (ISSN 1678-698X) http://www.periodicos.rc.biblioteca.unesp.br/index.php/estgeo 
da monocultura exportadora; da modernização das regiões competitivas, houve um desdobramento espacial: o crescimento da vida urbana com a concentração da população em alguns centros urbanos. Mas não se tratava apenas do deslocamento de trabalhadores do campo para as cidades, nem tampouco da concentração urbana em metrópoles e megalópoles. O que estava em curso era uma vida urbana, a imposição de uma cultura urbana, de uma cultura do habitar. Cada vez mais campo e cidade se pressupunham, um agindo em função do outro, ambos respondendo às contradições de uma sociedade mundializada.

Desse processo a alteração do trabalho, da luta de classe, da divisão regional do trabalho iam culminar com alterações em todas as práticas espaciais. Ou seja, o denominado modo de vida, cada vez mais mercantilizado e, por isso, com a vida subordinada à lógica do dinheiro e da compra, ia sendo acoplado a um regime simbólico que visava alterar os gostos, os desejos, as representações. A força da propaganda, do marketing, da publicidade e de toda a operação simbólica, como a linguagem, as formas de lazer, os hábitos cotidianos, seriam ideologizados pelas "grandes máquinas semiotizadoras" (GUATTARI \& ROLNIK, 1986), especialmente a mídia televisiva. A mercantilização ocuparia os dispositivos de coisas e especialmente de símbolos.

Os desdobramentos urbanos da chamada sociedade mundializada, sob a força da cultura de massa, da indústria do entretenimento, da indústria cultural, operavam conflitos geracionais a partir de valores sexuais, de modos de comportamento e também de significações afetivas e aos artefatos de vida.

Dessa feita, a análise dos efeitos da mundialização do capital, da implementação do neoliberalismo, das contradições de classe, das estratégias de resistências ou de enfrentamentos políticos, coloca o desafio de compreender a fragmentação do sujeito, as suas práticas espaciais, o mundo simbólico que lhe chegava e lhe dispunha, Ihe pressionava, Ihe acediava e lhe seduzia.

A rapidez, a força e a sedução desse sujeito chamado a consumir e a tentativa de padronizar os gostos, os desejos, iam promover uma reação. Os rompantes globalizadores hegemônicos desembocariam numa série de problemas estruturais, como a precarização do trabalho, o desespero causado pelo desemprego estrutural, o impacto no ambiente, a violência. Esses rompantes, além de compelirem os Estados a lidarem com uma contradição, pois se mostravam cada vez mais frágeis e menores para enfrentarem problemas mundializados e cada vez mais genéricos para enfrentarem problemas que aturdem os sujeitos, os lugares e as regiões, incidiam na reação política que se estendeu num círculo diverso e múltiplo.

Bandeiras como da raça-etnia; da sexualidade; do gênero; da alimentação; a inclusão de setores marginalizados; a organização dos denominados povos tradicionais e outra quantidade de defesas, pautas, reivindicações culminariam com um espectro diverso do tecido político, assim como das formas de reação, de organização e de desenvolver as representações de mundo.

No caso específico dos movimentos sociais contemporâneos, as lutas pelos direitos humanos, movimentos ecológicos ou ambientais, movimentos de mulheres, de mulheres negras, mobilizações pacifistas, fóruns mundiais, movimentos de atingidos por barragens; defensores de agroecologia, agricultura orgânica; movimento sem terra; movimentos pela casa própria; lutas de povos indígenas contra barragens, a favor da demarcação de terras e vários outros, mostram que as ações coletivas, no contexto da sociedade mundializada, põem em questionamento

Estudos Geográficos, Rio Claro, 16(2): $\quad$ 101-140, $\quad$ jul./dez. $2018 \quad$ (ISSN $\quad$ 1678-698X) http://www.periodicos.rc.biblioteca.unesp.br/index.php/estgeo 
e interrogação não apenas os preceitos da luta de classes, mas as dimensões simbólicas, os códigos de luta, de organização, as formas de leitura da realidade. Põem em questionamento não apenas os conteúdos dos Movimentos Sociais e de seus conteúdos políticos e ideológicos, mas o que são os Movimentos Sociais.

Ao falar do modo como Alberto Melucci, um dos maiores estudiosos do assunto, pensa os Movimentos Sociais contemporâneos, Queiroz (2003, p 120), esclarece que:

\begin{abstract}
Para Melucci as abordagens funcionalistas e marxistas dos anos 70 deixaram dois problemas sem resolver, visto que as teorias estruturais explicam por que, porém não como um movimento se estabelece e mantém sua estrutura; enquanto as teorias baseadas na mobilização de recursos explicam o como, porém não o porquê dos movimentos. Propõe então uma abordagem que possibilite a superação de tal dualismo, isto é, onde a ação seja considerada como uma "interação de objetivos, recursos e obstáculos; como uma orientação intencional que se estabelece dentro de um sistema de oportunidades e coerções". Apresenta em seguida uma definição analítica do movimento social como uma forma de ação coletiva que abraça as dimensões: da solidariedade, do conflito e de ruptura com os limites do sistema em que ocorre a ação. Para o autor é exatamente a presença destas três dimensões que permite que uma ação coletiva (definida como movimento social) seja separada de outros fenômenos coletivos. Se faltar uma dessas dimensões a ação coletiva não pode ser entendida como movimento social.
\end{abstract}

Observa-se, na análise do autor, que as críticas aos esteios clássicos da intepretação dos Movimentos Sociais introduzem outras categorias para definir o que é um Movimento Social. Baseando-se na ação coletiva e não apenas na ideologia, o autor enumera categorias que dão suporte a uma ação coletiva, marca do que, para ele, caracteriza os Movimentos Sociais contemporâneos.

Outro autor que tem os Movimentos Sociais contemporâneos como objeto de estudo argumenta favorável à mudança de compreensão desse agente político, Alan Touraine:

Propor nova definição e análise dos movimentos sociais, das características e das diversas interpretações elaboradas sobre eles, pode ser julgado como mais pernicioso do que útil. Atualmente, a única razão que me parece justificar um novo exame dessa noção é a introdução de outros elementos no debate. Aqui, duas possibilidades de crítica se apresentam. A primeira delas declara que a idéia de movimento social é menos uma categoria propriamente analítica do que uma categoria de natureza histórica. Isto é, os movimentos sociais estão ligados a um tipo de sociedade, que deixamos para trás, por exemplo, a sociedade industrial. A definição, entretanto, pode ter maior amplitude e, assim, não haver mais necessidade de utilizar a noção de movimentos sociais. Alguns dirão mesmo que é necessário deixar essa noção que nos fecha em um tipo de sociedade que, em grande parte, pertence ao passado, dando a impressão de nos oferecer um instrumento de análise geral (TOURAINE, 2006 p 19).

Estudos Geográficos, Rio $\quad$ Claro, $\quad$ 16(2): $\quad 101-140, \quad$ jul./dez. $2018 \quad$ (ISSN $\quad$ 1678-698X) http://www.periodicos.rc.biblioteca.unesp.br/index.php/estgeo 
A quase negação do que é Movimento Social em função do seu surgimento e sua operação serem frutos de um período histórico ligado à hegemonia da indústria, conduz o autor a uma justificativa:

Não há necessidade que um conflito social ou que uma ação coletiva se apresente armada de uma ideologia muito elaborada para que possamos concluir a presença de um movimento social. Inversamente, ideologias apelando a conflitos fundamentais na sociedade não são obrigatoriamente manifestações de um movimento social ou de antagonismos sociais. Afinal, a história está repleta de "pequenos" conflitos - com uma ação extremamente limitada na prática histórica -, fundados mais em significados do que em ideologias gerais. Qualquer que seja a flexibilidade com a qual nos empenharmos em referenciar a existência dos movimentos sociais - mediante conflitos ou iniciativas aparentemente mais limitadas -, é necessário considerarmos a definição que apresentei, por corresponder, durante longo período, ao pensamento social, especialmente no período central da sociedade industrial (TOURAINE, 2002, p. 20).

Ao ler as justificativas do sociólogo francês, pode-se insistir: o que define, caracteriza e justifica a existência dos Movimentos Sociais contemporâneos? Podese prescindir da ideologia em favor apenas da "ação coletiva"?

Convém fazer uma separação conceitual entre programas, mobilizações, organizações, projetos e Movimentos Sociais. Convém igualmente assentir que a interpretação de Movimento Social não é apenas uma referência teórica ou tampouco uma leitura do mundo. Trata-se de um posicionamento ideológico. Contudo, as determinações, os condicionamentos e as implicações de várias lutas de espectros urbanos e rurais envolvendo outros sujeitos, novas categorias, pautas, agendas e sentidos não podem ser desconsiderados. O que está colocado é a força da sociedade capitalista mundializada em reformular os conteúdos de classe, a organização do setor produtivo, os desafios do Estado e as condições concretas que conformam o sujeito social urbano e rural.

Antes de esboçar os pontos aos quais, a nosso ver, promulgam a constituição dos Movimentos Sociais, vale apresentar o que o geógrafo Marcelo Lopes de Souza entende pelo tema, usando, inclusive, uma separação conceitual entre ativismos sociais e movimentos sociais. Diz ele que,

Ativismos sociais são um conjunto mais amplo de ações públicas organizadas, do qual os movimentos sociais seriam um subconjunto ... Os movimentos sociais, de sua parte, seriam uma modalidade especialmente crítica e ambiciosa de ativismo social, distinta de ativismos "paroquiais". Estes encaminham reivindicações pontuais, sem articulá-las com questionamentos mais profundos, relativos a problemas nacionais e internacionais, e sem construir pontes entre a conjuntura, cujo domínio não ultrapassam, e as estruturas que não chegam a tematizar. São, não raro, prisioneiros do ou contaminados pelo clientelismo (2006, p. 278).

De acordo com o geógrafo o que define, qualifica e dá substância política aos Movimentos Sociais, são em primeira e última instância, a luta de classes,

Estudos Geográficos, Rio Claro, 16(2): 101-140, jul./dez. $2018 \quad$ (ISSN 1678-698X) http://www.periodicos.rc.biblioteca.unesp.br/index.php/estgeo 
entendendo-a no concerto histórico de um modo de produção concreto: o capitalismo. Considera-se também o seu modo de acumulação que historicamente define e desafia as lutas, os enfrentamentos, o caráter produtivo do trabalho, a sua organização. Por isso, Lopes enfatiza que o centro gravitacional dos Movimentos Sociais é a ideologia ou a visão de mundo que lhe dá suporte. Contudo, isso não significa descaracterizar a determinação de sua prática, que envolve tudo que se refere ao sujeito e à sua consciência. Ao Movimento Social cabe expor, defender e lutar para garantir a liberdade, a emancipação e o fim da exploração do trabalho e do sujeito, daí entra raça-etnia, sexualidade, alimentação, ambiente e outros quesitos presentes na vida.

Uma sociedade mundializada nutrida por aportes técnico-científicos, destruidora da biodiversidade, que estende o seu modo de acumulação nas esferas cotidianas da vida e interpela o sujeito com uma inflação de informações, signos, essa mesma sociedade que conduz o sujeito a viver em espaços urbanos concentrados e segregados, tem, por tendência, a criar um espaço e uma vida complexos. As lutas sociais adentram os territórios dessa complexidade, assim como os Movimentos Sociais.

Essa complexidade pode, contudo, distender as referências políticas e filosóficas, por exemplo a partir das lutas pontuais, particulares, ou dos sofrimentos específicos das chamadas identidades. Ou criar essencialismos políticos, próprios da espetacularização, da performance, ou de apropriações narcísicas dos diferentes discursos. Esse é um desafio dos Movimentos Sociais: articular lutas concretas, não cederem aos discursos performáticos, contudo com referências filosóficas que leem a totalidade do mundo objetivo. A práxis política como uma filosofia da ação, a ação ligada às referências alarga o raio da consciência e da ação total do sujeito envolvido. Daí ser também a pauta dos Movimentos Sociais todas as lutas que intercedem no sofrimento dos trabalhadores.

No momento atual, novos desafios se apresentam aos movimentos sociais, dados da conjuntura economia, política e ideológica, tais como: a judicialização da política, com um sistema judiciário cada vez mais movido por interesses políticos; criminalização dos movimentos sociais, com a prisão e perseguição de suas lideranças; militarização da sociedade, comprometendo inclusive a educação livre e emancipatória; ascendência de um imaginário social fascista, fortemente aportado nas redes sociais; conchavos político-partidários e midiáticos na articulação de golpes; vigilância ideológica aos profissionais de ensino de perfil progressista; falta de coesão de sentido no campo das esquerdas brasileiras, entre outros.

O fato é que a práxis eivada da consciência de classe convoca a vida total para ter uma deliberação política. Assim, não se pode dicotomizar as lutas pontuais, identitárias ou de ordens próximas da vida das lutas por uma sociedade emancipada e livre. Os movimentos sociais são partes do espaço e neles se vinculam.

\section{CONSIDERAÇÕES FINAIS}

A vida "imediata" se torna cada vez mais atravessada por forças de distintas ordens: econômica, política, semiótica. O estudo desse "fenômeno" ou "período histórico", por parte de muitos intelectuais, desemboca em termos como "invenção do cotidiano", "advento da cotidianidade", "reprodução da sociedade burocrática para o consumo" etc.

Estudos Geográficos, Rio Claro, 16(2): 101-140, jul./dez. $2018 \quad$ (ISSN 1678-698X) http://www.periodicos.rc.biblioteca.unesp.br/index.php/estgeo 
A fragmentação do tempo é, pois, um traço fundamental da sociedade moderna. Isso implica - ou ocorre simultaneamente - à captura das práticas espaciais por um modo de subjetivação que compromete a criatividade e a liberdade humana.

Compreender o avanço do capitalismo para o campo das práticas espaciais - e da subjetividade - permite, por outro lado, reconhecer as possibilidades de subversão obstruídas nesse mesmo campo. Ou seja, se a modernidade impede a existência de tempos e espaços próprios da dominação e da resistência, ela coloca todo o conjunto de relações sociais que constroem o território, passível de veicular conteúdos e práticas subversivas. A complexidade desse cenário exige que os movimentos sociais contemporâneos elaborem e empreendam táticas de resistência multiescalares, correlacionando a escala da geopolítica mundial ao mundo vivido.

\section{REFERÊNCIAS}

CHAVEIRO, E. Movimentos Sociais e Geografia. Inédito, 2017.

CHESNAIS, F. A mundialização do capital. Rio de Janeiro: Xamã, 1999.

CNPq - Conselho Nacional de Desenvolvimento Científico e Tecnológico. Diretório dos Grupos de Pesquisa. 2016. Disponível na internet (www.cnpq.br). Acesso em: fev. 2016.

FERNANDES, Bernardo Mançano. Movimento Social como categoria geográfica. In: Terra Livre: São Paulo, n.15, 2000.

GOHN, Maria da Glória et al. Abordagens teóricas no estudo dos movimentos sociais na América Latina. Caderno CRH, 2008. Disponível em: http://www.scielo.br/pdf/ccrh/v21n54/03. Acesso em: fev. 2018.

GUATTARI, Félix; ROLNIK, Suely. Micropolítica: cartografias do desejo. 4. ed. Rio de Janeiro: Editora Vozes Ltda, 1986.

PEDON, Nelson Rodrigo. Geografia e movimentos sociais: dos primeiros estudos à abordagem socioterritorial. Editora Unesp, 2013.

POIAN, Carmem Da. O Mal-estar contemporâneo: buscando saídas. Cad. Psicanál.-CPRJ, Rio de Janeiro, v. 33, n. 24, p. 30-39, 2011. Disponível em: http://www.cprj.com.br/imagenscadernos/caderno24_pdf/13_CP_24_O_MAL-ESTAR CONTEMPORANEO.pdf. Acesso em: mai. 2015.

PORTO-GONÇALVES, Carlos Walter; SEOANE, José. A geograficidade do social. Movimientos sociales y conflic-to en América Latina. Buenos Aires: CLACSO, 2003. Disponível em: biblioteca.clacso.edu.ar/ar/libros/osal/seoane /porto.rtf. Acesso em: fev. 2018.

QUEIROZ, Imar Domingos. As ações coletivas na sociedade contemporânea. Em Tese, $\quad v$. $1, \quad$ n. $1, \quad 2003 . \quad$ Disponível em: https://periodicos.ufsc.br/index.php/emtese/article/view/13714. Acesso em: jan 2018.

Estudos Geográficos, Rio Claro, 16(2): 101-140, jul./dez. $2018 \quad$ (ISSN 1678-698X) http://www.periodicos.rc.biblioteca.unesp.br/index.php/estgeo 
RAMOS, Tatiana Tramontani. A Dimensão Espacial das Lutas Sociais. Revista Continentes, n. 2, p. 96-123, 2013. Disponível em: http://www.revistacontin entes.com.br/continentes/index.php/continentes/article/view/20. Acesso em: jan 2018.

ROLNIK, Raquel. Guerra dos Lugares: a colonização da terra e da moradia na era das finanças. 1르. ed. São Paulo: Boitempo, 2015.

SANTOS, Renato Emerson dos. Política de cotas raciais nas universidades brasileiras: o caso da UERJ. Ação afirmativa e universidade: experiências nacionais comparadas. Brasília: UnB, 2006.

SOUZA, Marcelo L. Dos espaços de controle aos territórios dissidentes. - $1^{\text {a }}$ ed. Rio de Janeiro (RJ): Editora Consequência, 2015.

TOURAINE, Alain. Na fronteira dos movimentos sociais. Sociedade e Estado, v. 21, n. 1, 2006. Disponível em: http://www.scielo.br/pdf/se/v21n1/v21n1a03. Acesso em jan. 2018.

Artigo submetido em: 17/05/2018

Aceito para publicação em: 04/11/2018

Publicado em: 14/12/2018

Estudos Geográficos, Rio Claro, 16(2): 101-140, jul./dez. $2018 \quad$ (ISSN 1678-698X) 